Article

\title{
Design of a Hydraulic Motor System Driven by Compressed Air
}

\author{
Dein Shaw *, Jyun-Jhe Yu and Cheng Chieh \\ Department of Power Mechanical Engineering, National Tsing-Hua University, Hsin-Chu City 30013, \\ Taiwan; E-Mails: u9633213@oz.nthu.edu.tw (J.-J.Y.); u9733131@oz.nthu.edu.tw (C.C.) \\ * Author to whom correspondence should be addressed; E-Mail: dishaw@pme.nthu.edu.tw; \\ Tel.: +886-3-574-2604; Fax: +886-573-9979.
}

Received: 25 February 2013; in revised form: 18 June 2013 / Accepted: 18 June 2013 /

Published: 27 June 2013

\begin{abstract}
This paper presents the design of a highly efficient pneumatic motor system. The air engine is currently the most generally used device to convert potential energy of compressed air into mechanical energy. However, the efficiency of the air engines is too low to provide sufficient operating range for the vehicle. In this study, the energy contained in compressed air/pressurized hydraulic oil is transformed by a hydraulic motor to mechanical energy to enhance the efficiency of using air power. To evaluate the theoretical efficiency, the principle of balance of energy is applied. The theoretical efficiency of converting air into hydraulic energy is found to be a function of pressure; thus, the maximum converting efficiency can be determined. To confirm the theoretical evaluation, a prototype of the pneumatic hydraulic system is built. The experiment verifies that the theoretical evaluation of the system efficiency is reasonable, and that the layout of the system is determined by the results of theoretical evaluation.
\end{abstract}

Keywords: air engine; pneumatic engine; hydraulic motor; efficiency; air car engine design

\section{Introduction}

With the currently rising oil prices and greenhouse gas emissions, transportation technology that is not based on oil is urgently required; it must be sufficiently clean and affordable. Compressed air technology can be a solution; compressed air is commonly used in the industry because its production and handling are safe and easy [1]. 
A compressed air car, also called a pneumatic car, is considered an environmentally friendly vehicle, and has been promoted by companies, such as Motor Development International (Luxembourg, French), MDI and Energine (Seoul, Korea) [2]. One well-known commercial product, the MDI AIRPod [3], is a small three-wheel car with three seats. Furthermore, certain prototypes, such as the $\mathrm{Ku}$ :Rin by Toyota (Toyota City, Japan) [4], the $\mathrm{O} 2$ pursuit, and a pneumatic motorcycle with an EngineAir engine built by Senstead [5] have been introduced.

Compressed air cars share the same advantages as electrical cars in substituting for gasoline-driven vehicles. However, on a normal car scale, electrical cars outperform compressed air cars in every category such as life-cycle analysis. The real progress in compressed air cars may be the emphasis on light and small vehicles [2] and the low investment and maintenance costs [1]. For example, it may substitute gasoline-powered motorcycles in Taiwan [6]. However, because of the low total efficiency, including air compression and expansion efficiency, the energy cost of compressed air is currently more expensive than gasoline [1]; however, this can be improved in the future by green power plants such as the plants built by PG\&E (San Francisco, CA, USA) in San Francisco [7], whereas the cost of gasoline cars cannot be improved by using the green electric power.

In addition to the high energy cost, operating range is also a serious concern for compressed air cars. Therefore, a highly efficient methodology to convert energy is required. Engineers have invented numerous types of pneumatic motors; the following are some common motors: In 1902, Werner [8] invented a four-chamber rotary engine, and Quasiturbine Company (Montreal, Canada) used this as an air motor. This type of air motor can produce a high torque at low revolutions per minute [9]. In 2009, Shen and Hwang [6] built an air-powered motorcycle with a vane-type motor from GAST Company (Benton Harbor, MI, USA), which ran with best efficiency at $20 \mathrm{~km} / \mathrm{h}$. Vane-type motors have been well recognized in industrial and automotive use [10]. Further details on vane-type motors can be found by catalogs and efficiencies up to $19 \%$ can be reached. In 2011, Hu [11] built a piston-type air motor based on an IC engine from a scooter and investigated the performance and efficiency of a piston-type motor. This piston-type engine had an efficiency of $13 \%$ at 4 bar and $1200 \mathrm{rpm}$. In 2007, Requsci [12] patented his pneumatic free-piston motor, which is easy to install on bicycles.

The key to improving efficiency is reducing the residual pressure of the exhaust air [11]. The engine in the MDI AirPod is a piston-type motor with two steps. After the compressed air enters the first cylinder and expands, the air enters the second cylinder and expands, causing the pressure to drop more than that in an engine with one cylinder [13]. In 2005, Di Pietro [14] designed an improved vane-type motor. A rotary valve controls the volume of intake air, and the exhaust timing is also controlled so the pressure of intake air drops to a low level. This motor is produced by EngineAir Company (Melbourne, Australia).

Hydraulic power has had a part in pneumatic systems for the past few decades. In 1973, Otto [15] designed a machine for converting compressed air energy into mechanical energy. Thomas used two cylinders as the air/oil converter in his machine. The compressed air entered one of the cylinders to push the liquid and drive the piston and crankshaft. Four valves are controlled by linkages for controlling the intake and exhaust timing of the compressed air to maintain system operation. In 2004, Wu et al. [16] designed a transmission system for vehicles named the Hydraulic Hybrid Delivery. The transmission consists of two accumulators and a pair of pump/motors, which either can be pumps or 
motors. To maintain the IC engine speed in the efficient range, the system uses the superfluous energy of the IC engine to pump the liquid into the accumulators to store energy by compressing air in the accumulator. When the vehicle accelerates, the system releases the compressed air energy in the accumulator to enable the motor and vehicle to accelerate. The system can also trap the kinetic energy of the vehicle when it is braking. The efficiency of the pump/motor is over $90 \%$ when used as either a pump or motor [17].

In this study, compressed air is used to drive a hydraulic motor to take advantage of the high efficiency of hydraulic motors to enhance total efficiency of the system. A large volume of air is used for each step of air expansion to increase the expansion duration. Longer expansion duration reduces the energy losses during the air intake and leads the heat of surrounding transfer into the air to improve the efficiency. Through the valves and tube, the pressurized hydraulic oil drives the hydraulic motor continuously. To convert the air pressure to hydraulic pressure, an air/oil converter is used.

Section 2 presents the entire system layout, which consists of air/oil converters, valves, and a hydraulic motor. In the system, the compressed air flows into the air/oil converter and push the oil out to convert the air energy into hydraulic energy; hydraulic energy efficiency is detailed in Section 3 of this study. Section 4 shows the experiments and presents a comparison of the system efficiency of the theoretical and experimental results. Finally, a conclusion is made.

\section{System Layout}

In this section, the system layout and the operating processes are introduced. The system layout used to achieve high efficiency in transforming compressed air energy into mechanical energy is shown in Figure 1. A tank, air directional valves, air/oil converters, hydraulic directional valves, air pipes, oil pipes, a hydraulic motor, and the hydraulic oil in the system are shown. In this study, the elements on the right side are denoted with an R; the left side is denoted with an L.

Figure 1. The system layout.

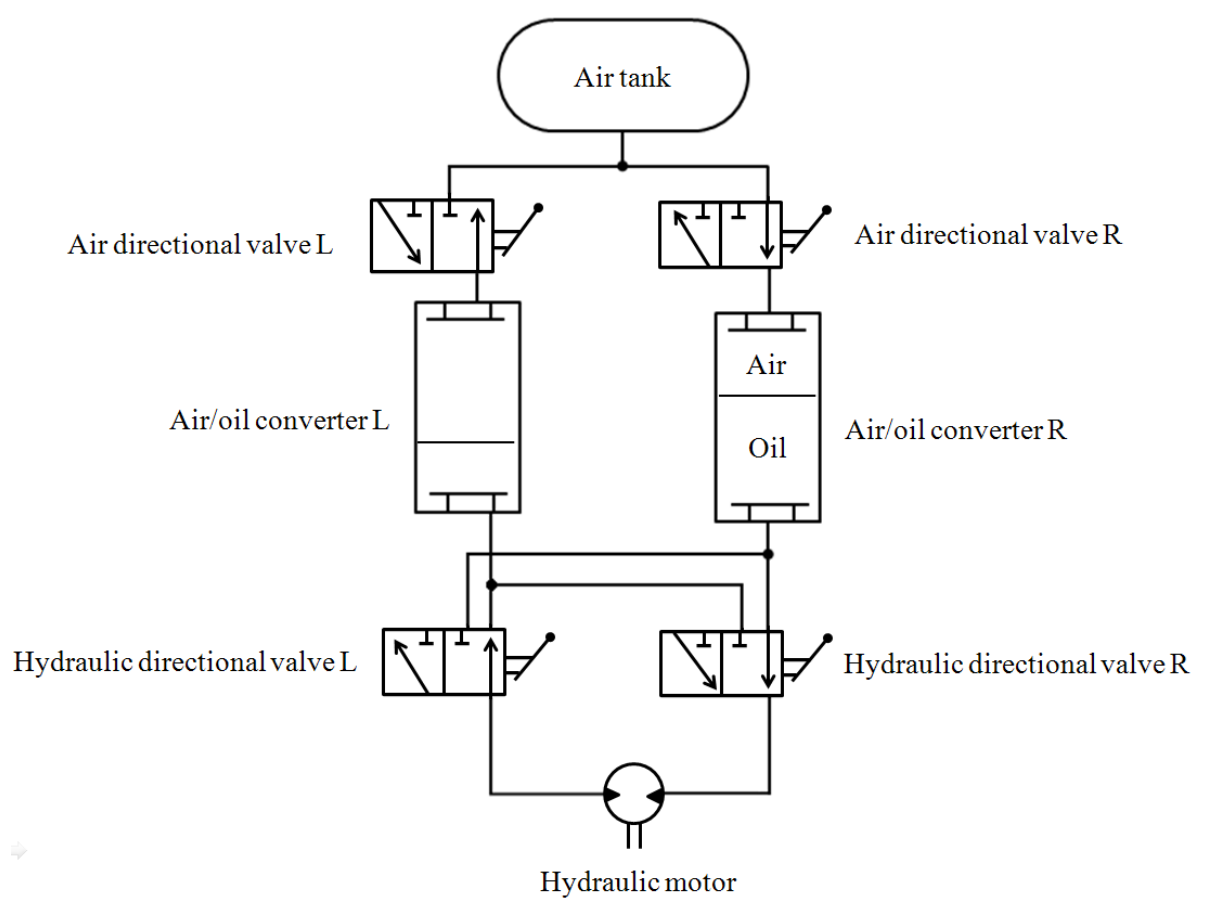


The compressed air is stored in the tank, exits the tank, and enters the air/oil converter. Through the air/oil converter, the compressed air pushes the oil out of converter and the converter becomes an oil pressure source. Finally, the oil from the converter drives the hydraulic motor.

The air and hydraulic directional valves control the directions of the fluid to operate the motor. According to the flow direction, the system layout is divided into two phases: A and B, as shown in Figure 2a,b.

Figure 2. The system working process. (a) The phase A and (b) the phase B.

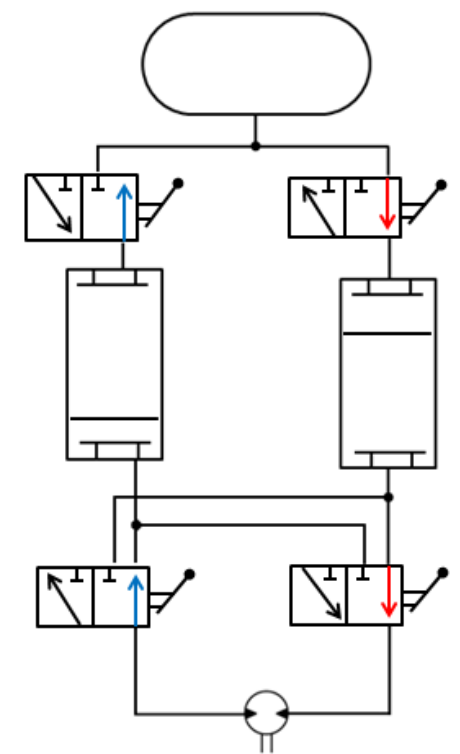

(a)

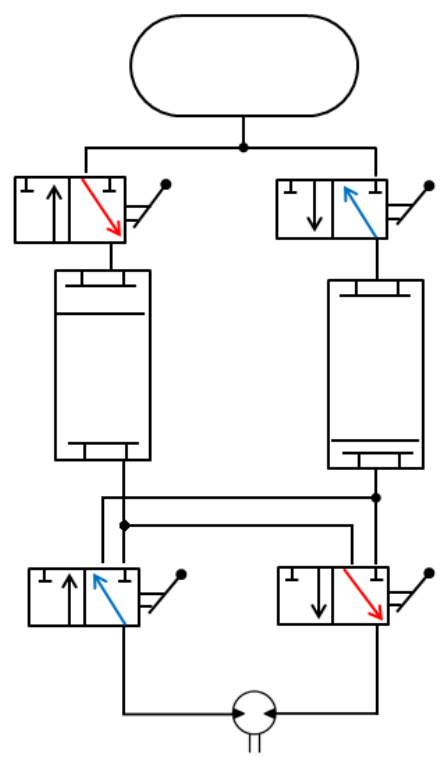

(b)

In Phase $\mathrm{A}$, the air directional valve $\mathrm{R}$ leads the compressed air from the tank to the air/oil converter R. In converter R, the compressed air produces hydraulic oil pressure. The hydraulic directional valve $\mathrm{R}$ directs the high-pressure oil to the motor so that the motor begins to rotate and the oil pressure drops after passing the motor. Thereafter, the depressurized oil leaves the motor and enters air/oil converter L via hydraulic directional valve L. During this time, air directional valve L is pointed in the exhaust direction so that the air is pushed out of the converter $L$ when the oil enters. When converter $\mathrm{L}$ is full of oil, the Phase A process is finished.

Before the beginning of Phase $\mathrm{B}$, air directional valve $\mathrm{R}$ is switched to the exhaust direction to discharge the residual air in converter $\mathrm{R}$. Air directional valve $\mathrm{L}$ is switched to the intake direction. The compressed air then drives the hydraulic motor similar to the manner in Phase A. When Phase B ends, air directional valve $\mathrm{L}$ is switched to the exhaust direction to operate Phase A once again. By repeating Phases $\mathrm{A}$ and $\mathrm{B}$, the system works continuously, and the motor rotates in the same direction.

\section{Efficiency Analysis of Converting Air Pressure into Oil Pressure}

The air/oil converter (herein known as the "converter") is used to convert the air pressure to oil pressure. During the conversion process, the compressed air pressurizes the oil and the oil is push out of the converter by the air. Since the oil can be reused, the oil from the converter should then enter another converter, which is used as a reservoir. Section 2 showed the procedure of the entire system. If 
the air exhaust from the system has a high residual pressure, some energy is lost with the high-pressure air. In this section, the efficiency of the conversion is evaluated by using the principle of energy balance. Two methods are proposed to operate the converter in this study. The first is called constant pressure operation, in which the compressed air flows into the converter and produces oil with a constant pressure until the oil in the converter drains out. The second method is expansion operation. After the proper quantity of compressed air enters the converter, the intake valve is closed. The compressed air then expands to drain out the oil. The second operation method can reduce the pressure of the exhaust air to improve efficiency. It is noted that the mater (both air and oil) in the converter is always follow in (air) and out (oil) of the converter; the converter is an open system. However, if we only count on the compressed air, the system some time is open system and some time is closed system depending on what step the system is.

\subsection{Constant Pressure Operation Mode}

The system is assumed to start with phase A, we analysis the converter at the right hand side of Figure 2a. The operation begins with the converter full of oil, as shown in Figure 3a. The intake valve causes the compressed air of pressure $P$ to flow into the converter and pressurizes the oil, which produces the oil pressure source (Figure 3b). As soon as the oil in the converter is pushed out completely, the intake valve closed. At that time, the converter is full of compressed air, as shown in Figure $3 \mathrm{c}$, then the converter discharges the compressed air to the atmosphere at a pressure of $P_{\text {atm }}$ to reduce the air pressure in the converter, and the system start the phase $\mathrm{B}$, the convertor of right hand side of Figure 2 is then used as a reservoir of oil and left hand side converter is now work as the right hand side converter in phase $\mathrm{A}$, as shown in Figures $2 \mathrm{~b}$ and $3 \mathrm{~d}$. Thereafter, the oil flows back into the converter with the exhaust valve open until the converter is full of oil again (Figure 3e). This is the cycle of constant pressure operation. In Figure 3, the operational pressure is $P$, the atmospheric pressure is $P_{a t m}$, and the volume of the air/oil converter is $V_{c}$. It is noted that only the step shown in Figure $3 \mathrm{~b}$ can output the energy to the hydraulic motor. Therefore, only the energy input and output of this step are studied.

Figure 3. (a) The converter is full of oil at pressure $P_{\text {atm }}$; (b) Compressed air enters the converter to push the oil out at pressure $P$; (c) The converter is full of compressed air at pressure $P$; (d) The converter discharges the compressed air into the atmosphere; and (e) The oil flows back and pushes the air out at pressure $P_{\text {atm }}$.

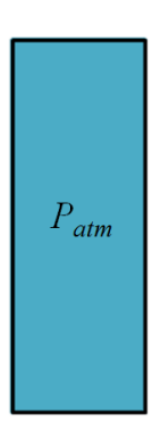

(a)

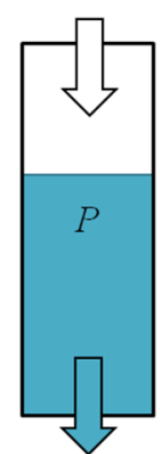

(b)

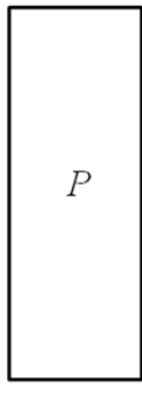

(c)

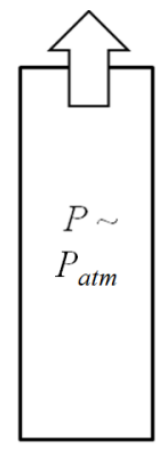

(d)

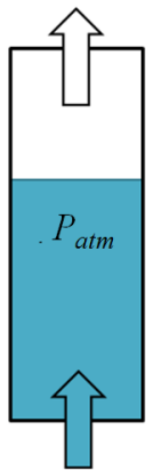

(e) 


\section{Constant Pressure Operation Efficiency Analysis}

A physical model of the air/oil converter of the operating step of Figure $3 b$ is analyzed as shown in Figure 4. In Figure 4, $\dot{E}_{i}$ is the energy rate of the compressed air enters the converter. $\dot{E}_{e}$ is the rate of energy of oil discharged from converter which drives the motor to output the kinetic energy. $\dot{Q}_{\text {in }}$ is the energy rate of heat transfer into the converter from environment. To simply the mathematic model, following assumption are made for the analysis of converter:

1. The air is act as an idea gas;

2. The hydraulic oil is incompressible;

3. The velocity and the height change of the fluids are neglected due to the required oil flow rate of the chosen hydraulic motor is small, which under this assumption, the kinetic energy and the potential energy changes are assumed to be zero;

4. There is no pressure loss at entering and discharging valves;

5. According to the experiment (the setup will be discussed in the experiment section of this study) results, the temperature in the converter is constant.

The efficiency of the air/oil conversion under the constant pressure operation $\eta$ is defined as:

$$
\eta=\frac{E_{e}}{E_{\text {Total }}}
$$

In above equation, $E_{\text {Total }}$ is the total energy provided by compressed air, which is the sum of the $E_{e}$ and energy in the compressed air $E_{c}$ of a full converter of compressed air.

Figure 4. The energy balance of the converter.

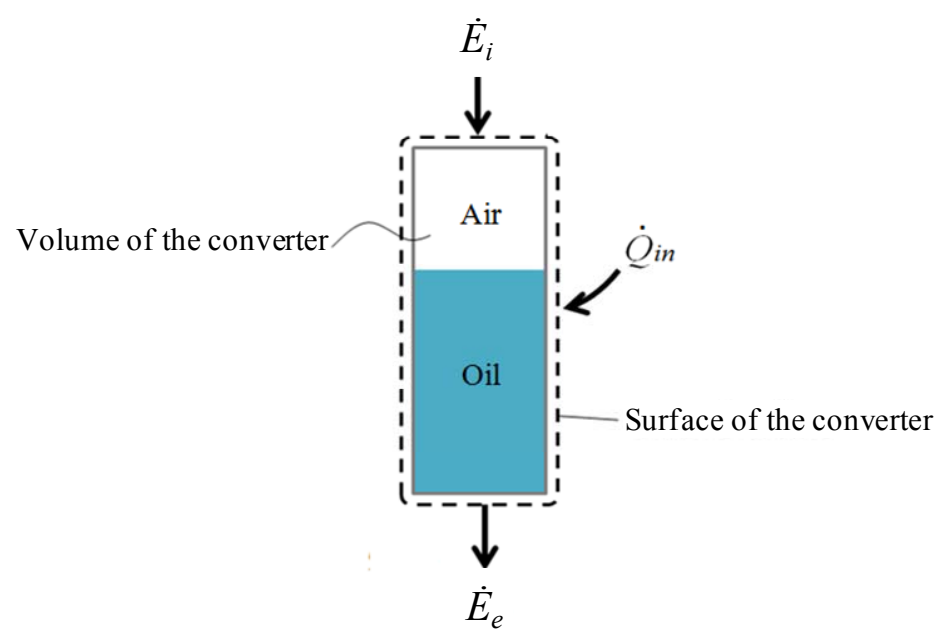

As shown in Figure 4, follows the balance of energy, the system satisfies:

$$
\frac{d E_{s}}{d t}=\dot{Q}_{i n}+\dot{W}_{\text {in }}+\dot{E}_{i}-\dot{E}_{e}
$$

In the above equation $E_{s}$ is the energy store in the converter at step of Figure $3 \mathrm{~b}$, in this case it is zero. $\dot{W}_{\text {in }}$ is the work input into the converter. Because there is no air expansion in the converter at this step, there is no temperature change and therefore $Q_{i n}$ is zero. After above discussion, according to Equation (2), it means the $E_{i}$ carried by compressed air is equal to the energy discharge from converter 
$E_{e}$ carried by the oil. It is noted that the pressure of compressed air is constant at operation. The ideal $\mathrm{P}-\mathrm{V}$ diagram in the converter is presented in Figure 5.

Figure 5. The ideal P-V diagram of constant pressure operation.

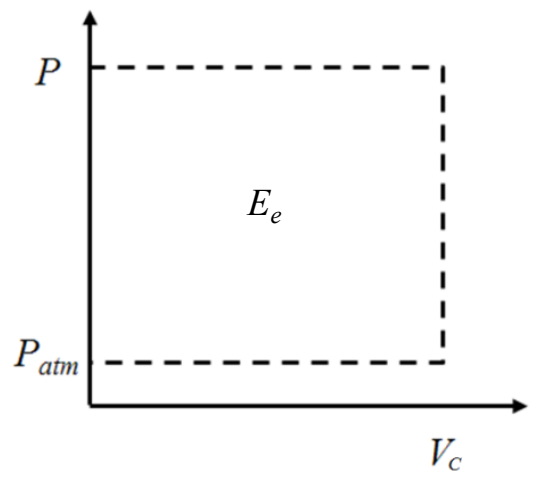

$E_{e}$ is the integral area inside the dotted line in Figure 5, and it yields:

$$
E_{e}=E_{i}=\int\left(P-P_{a t m}\right) d V=\left(P-P_{a t m}\right) V_{c}
$$

To find the total energy input to the converter, energy $E_{c}$ in a converter full of compressed air when the hydraulic system completes half cycle of operation, which is equal to the work done by compressing the air of absolute pressure $P_{a t m}$ and volume $V_{\text {atm }}$ to absolute pressure $P$ and volume $V_{c}$ under the adiabatic assumption. The relation of pressure and volume can be expressed as:

$$
P^{\prime} V^{\prime \gamma}=P V_{C}^{\gamma}=P_{a t m} V_{a t m}^{\gamma}
$$

$E_{c}$ can be found in following equation:

$$
\begin{aligned}
E_{C} & =\int_{1}^{2} P^{\prime} d V^{\prime}-P_{a t m}\left(V_{a t m}-V_{C}\right)=P V_{C}^{\gamma} \int_{1}^{2} \frac{d V}{V^{\prime \gamma}}-P_{a t m}\left(V_{a t m}-V_{C}\right) \\
& =\frac{P V_{C}{ }^{\gamma}}{1-\gamma}\left[V_{a t m}{ }^{1-\gamma}-V_{C}{ }^{1-\gamma}\right]-P_{a t m}\left(V_{a t m}-V_{C}\right)
\end{aligned}
$$

Furthermore, $V_{\text {atm }}$ equals $V_{c}\left(P / P_{a t m}\right)^{1 / \gamma}$ from Equation (4), $E_{c}$ becomes:

$$
\begin{aligned}
E_{c} & =\frac{P V_{C}^{\gamma}}{1-\gamma}\left[\left(\frac{P}{P_{a t m}}\right)^{\frac{1}{\gamma}-1} V_{C}^{1-\gamma}-V_{C}^{1-\gamma}\right]-P_{a t m}\left(V_{a t m}-V_{C}\right) \\
& =\frac{P V_{C}}{1-\gamma}\left[\left(\frac{P}{P_{a t m}}\right)^{\frac{1}{\gamma}-1}-1\right]-P_{a t m}\left(V_{a t m}-V_{C}\right)
\end{aligned}
$$

Combining Equations (3) and (6), and the total energy $E_{\text {Total }}$ into the tank yields:

$$
\mathrm{E}_{\text {Total }}=E_{e}+E_{c}=\left(P-P_{a t m}\right) V_{c}+\frac{P V_{C}}{1-\gamma}\left[\left(\frac{P}{P_{a t m}}\right)^{\frac{1}{\gamma}-1}-1\right]-P_{a t m}\left(V_{a t m}-V_{C}\right)
$$

Combining Equation (1) with Equations (3), (4) and (7), one may get: 


$$
\begin{aligned}
& \eta=\frac{\left(P-P_{a t m}\right) V_{c}}{\left(P-P_{a t m}\right) V_{c}+\frac{P V_{C}}{1-\gamma}\left[\left(\frac{P}{P_{a t m}}\right)^{\frac{1}{\gamma}-1}-1\right]-P_{a t m}\left(V_{a t m}-V_{C}\right)} \\
& =\frac{\left(P-P_{a t m}\right)}{P-P_{a t m}\left(\frac{P}{P_{a t m}}\right)^{1 / \gamma}+\frac{P}{1-\gamma}\left[\left(\frac{P}{P_{a t m}}\right)^{\frac{1}{\gamma}-1}-1\right]}
\end{aligned}
$$

Equation (8) shows that the efficiency here is only concerned with compressed air pressure $P$. Regarding the experiments, the gauge pressure is more suitable to use than the absolute pressure. Therefore, the efficiency of the air/oil conversion $\eta$ versus the operating gauge pressure $P$ - $P_{\text {atm }}$ bar is plotted in Figure 6. However, the operating gauge pressure below 4 bar is unable to drive the hydraulic motor of the prototype, will be discussed in Section 4; the data under 4 bar are plotted with a dotted line.

Figure 6. The converting efficiency under constant pressure operation.

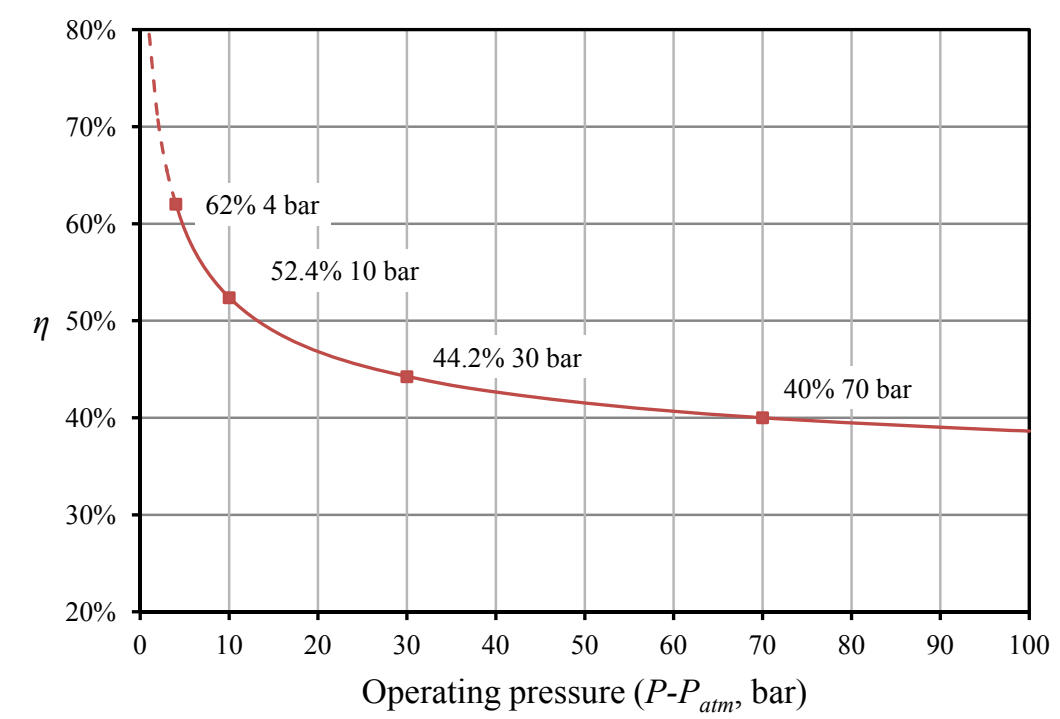

\subsection{Expansion Operation Mode}

The expansion-operation procedures are shown in Figure 7. It begins with the converter full of oil; the intake valve allows the compressed air to enter the converter as it works in constant pressure operation mode, as shown in Figure 7a,b. The intake valve closed at the time a proper quantity of compressed air enters the converter. The partial volume $V_{d} / N$ of the converter is then charged by the compressed air, as shown in Figure 7c. $N$ is defined as the ratio of the total volume of the converter to the charged volume, $N \geq 1$. The compressed air at pressure $P$ then begins to expand until the oil in the converter drains out; the pressure drops to the residual pressure $P_{\text {res }}$, as shown in Figure $7 \mathrm{~d}$. After that the converter discharges the residual air to the atmosphere, and the oil from the converter of another side of the system flows back to the converter (Figure 7e,f). The addition pressure-dropping step than constant pressure mode should improve the efficiency of the system. 
Figure 7. (a) The converter is full of oil; (b) Compressed air enters the converter; (c) The converter is charged by the compressed air at pressure $P$ and volume $V_{d} / N$; (d) The compressed air expands to pressure $P_{\text {res }}$; (e) The converter discharges the residual air to the atmosphere; and (f) The oil flows back in and push the air out at an atmospheric pressure.

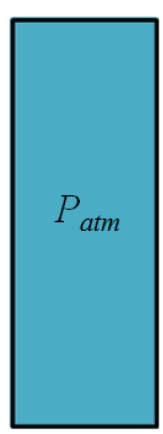

(a)

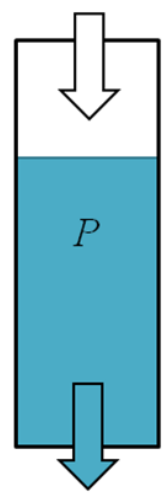

(b)

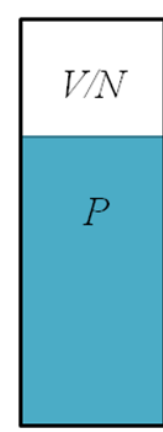

(c)

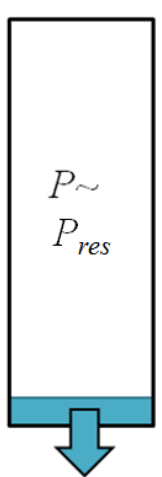

(d)

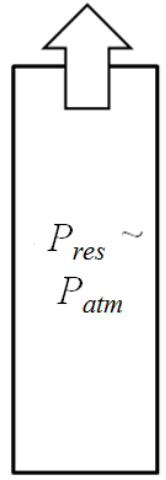

(e)

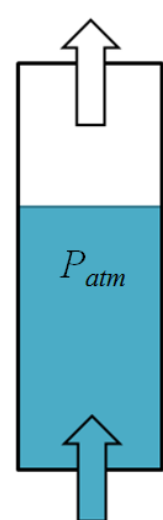

(f)

\section{Expansion Operation Efficiency Analysis}

To analysis the efficiency of the expansion operation mode, the first thing to do is to find the steps which output the energy. It was found that only two step shown in Figure 7c,d are involved. At the step in Figure 7c, the compressed air of absolute pressure $P$ and volume $V_{c} / N$ enters the converter. At the step in Figure $7 \mathrm{~d}$, the air is expanded to pressure $P_{\text {res }}$ and volume $V_{c}$. During the expansion, the energy $Q_{\text {in }}$ transfers from the surroundings into the converter by heat transfer to keep the fluids in the converter at room temperature (this assumption is due to the observation of the experiments of this study). The P-V diagram of the steps of Figure 7c,d are shown in Figure 8. It is noted that the step of Figure $7 \mathrm{~d}$ is an isothermal process. Therefore, $\gamma$ is equal to 1 in Equation (4) when used in this step.

Figure 8. The ideal P-V diagram of the expansion operation.

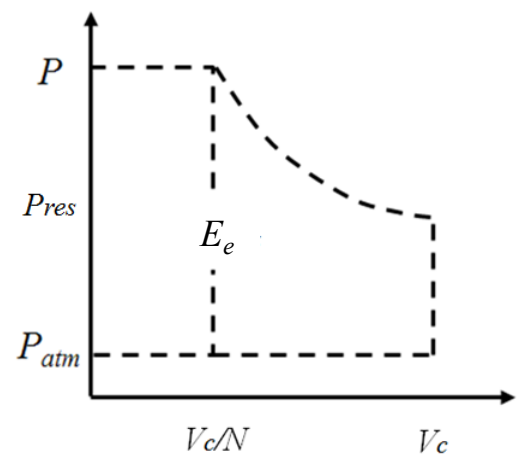

$E_{e}$ is evaluated under the constant temperature assumption and according to integrate results of Figure 8 , the equation yields:

$$
E_{e}=\left(P-P_{a t m}\right) \frac{V_{c}}{N}+P\left(\frac{V_{c}}{N}\right) \ln \frac{V_{c}}{\frac{V_{c}}{N}}-P_{a t m}\left(V_{c}-\frac{V_{c}}{N}\right)
$$


The assumptions for evaluating $E_{\text {Total }}$ of this section are different from the assumptions for evaluating $E_{e}$. An adiabatic assumption is more reasonable for evaluating $E_{\text {Total }}$ because $E_{\text {Total }}$ presents the energy only performed by the tank but not the energy of heat transfer from the surroundings. Similar way to the evaluation of $E_{e}$ in Figure 8 (only difference is that $\gamma$ is not equal to 1 ), one may integrates Figure 8 to get $E_{e}$ of adiabatic condition. The energy $E_{c}$ store in the compressed air of pressure $P$ and volume $V_{c} / N$ can also found in Equation (4). Add those two together, one may get $E_{\text {total }}$ :

$$
E_{\text {Total }}=\left(P-P_{a t m}\right) \frac{V_{c}}{N}+\frac{P \frac{V_{c}}{N}}{1-\gamma}\left[\left(\frac{P}{P_{a t m}}\right)^{\frac{1}{\gamma}-1}-1\right]-P_{a t m}\left(V_{a t m}-\frac{V_{c}}{N}\right)
$$

Balance of energy in Equation (2) is still satisfied.

Substitute Equations (9) and (10) into Equation (1) and $V_{\text {atm }}$ equals $\left(V_{c} / N\right)\left(P / P_{a t m}\right)^{1 / \gamma}$. The expansion operation efficiency $\eta$ can then be found as:

$$
\eta=\frac{P+P \ln N-P_{a t m} N}{P-P_{a t m}\left(\frac{P}{P_{a t m}}\right)^{1 / \gamma}+\frac{P}{1-\gamma}\left[\left(\frac{P}{P_{a t m}}\right)^{(1 / \gamma)-1}-1\right]}
$$

Equation (11) shows that the efficiency here concerns not only compressed air pressure $P$ but also the ratio of charged volume $N$. After the constant temperature expansion, the residual pressure $P_{\text {res }}$ in the converter is $P / N$. The efficiency of $\eta$ versus the operating gauge pressure $P$ - $P_{\text {atm }}$ bar with different ratios of charged volumes $N$ is plotted as shown in Figure 9. The data plotted in the dotted lines indicate that the residual pressure is lower than the gauge pressure at 4 bar. Figure 9 shows that the efficiency is higher with a lower operating pressure and a larger $N$.

Figure 9. The converting efficiency under the expansion operation.

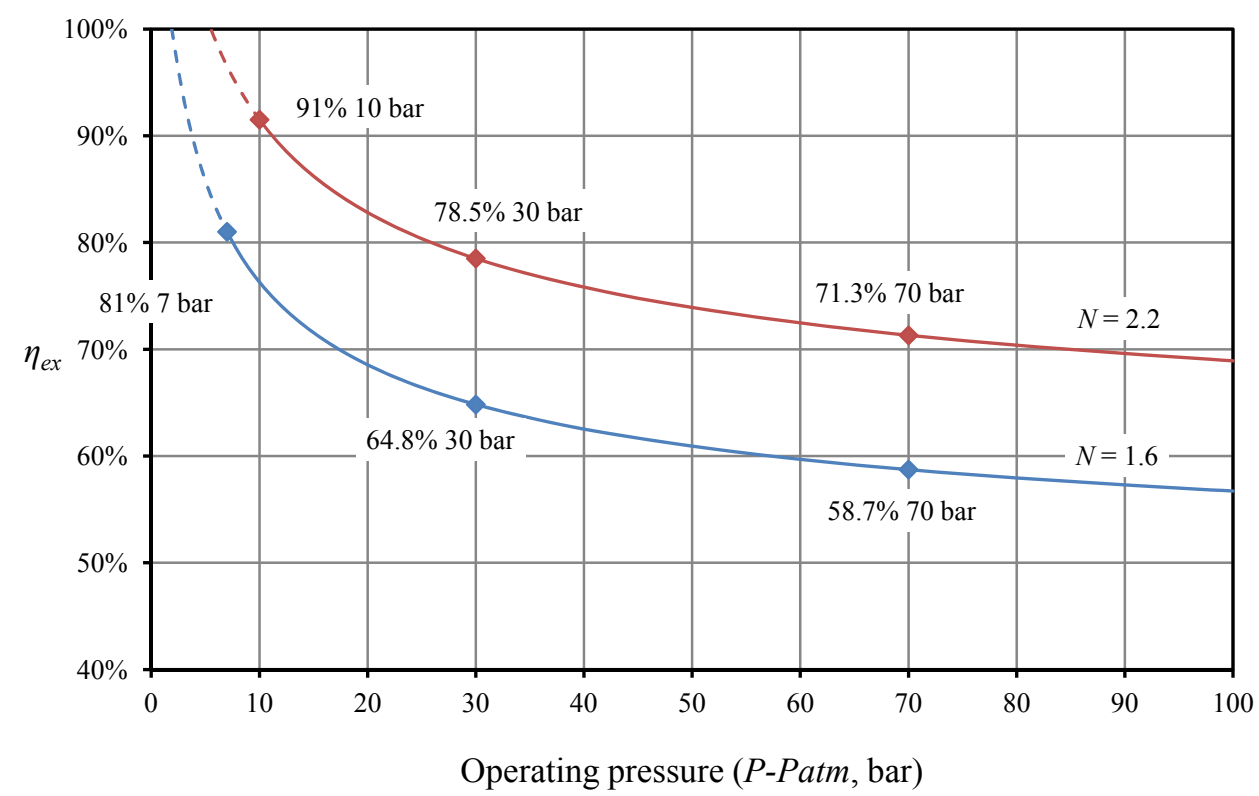




\section{Experiment, Results, and Comparison}

\subsection{Prototype Construction}

To verify the efficiency analysis result, a system prototype was built. This section introduces the experiment methods and the elements used in the prototype.

The air/oil converter in this study is Mindman MCQA-AH; the specifications are as follows: $10 \mathrm{~cm}$ diameter, $50 \mathrm{~cm}$ height, $4 \mathrm{~L}$ volume, the operating pressure range is 0.5 to $9.9 \mathrm{bar}$, and the proof pressure is 15 bar. A sheet of metal is placed to prevent the compressed air from splashing the oil into the converter, as shown in Figure 10.

Figure 10. Inside the air/oil converter.

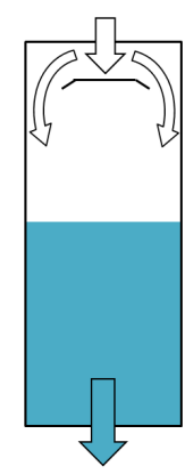

The hydraulic motor is a SAUER DANFOSS OMM8 internal gear motor, as shown in Figure 11 [18]. The rotor rotates in the case, and the oil flows into the gap between the rotor and the case to drive the motor. The maximum efficiency of this motor is $73 \%$ when the operating pressure is 70 to 125 bar, and the output range is 370 to $1500 \mathrm{~W}$ when the flow rate is 4 to $12 \mathrm{~L} / \mathrm{min}$.

Figure 11. Inside the SAUER DANFOSS hydraulic motor.

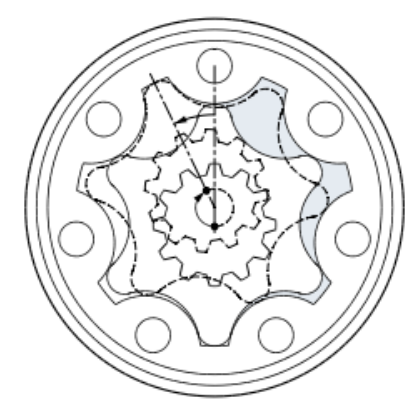

The prototype of the system layout, mentioned in Section 2, is built, as shown in Figure 12. Although the maximum efficiency of the motor is $73 \%$ at a pressure of 70 bar, the operating pressure in normal pneumatic parts and air compressors is approximately 10 bar. Thus, the operation pressure of the prototype in this study is set at 10 bar for preliminary verification.

In the prototype, a compressor with a tank of air pressure 12 bar and volume $170 \mathrm{~L}$ is a good substitute for a high pressure tank. The general compressed air tank for a light vehicle is operated at storage pressure $300 \mathrm{bar}$, operation pressure 7 to $10 \mathrm{bar}$ and volume 50 to $200 \mathrm{~L}$ and takes about 10 to 
$20 \mathrm{~min}$ to refill. Then the air directional valves are replaced by ball valves for the advantage of low-flow resistance and less vibration. The hydraulic directional valves are spool manual valves. The rotation speed of the motor is controlled by the break shown in Figure 12.

\subsection{Hydraulic Motor Efficiency Measurement}

The efficiency of the hydraulic motor alone $\eta_{\text {motor }}$ follows a well-known equation:

$$
\eta_{\text {motor }}=\frac{\tau \times \omega}{\Delta P \times q_{\text {oil }}}
$$

where $\tau$ is the torque produced by the motor; $\omega$ is the rotational speed of the motor; $q_{\text {oil }}$ is the volume flow rate of the oil; and $\Delta P$ is the pressure difference between the inlet and outlet of the motor. Furthermore, the pressure at the outlet is measured at atmospheric pressure; thus, $\Delta P$ is also the gauge pressure of the inlet pressure.

Figure 12.The prototype.

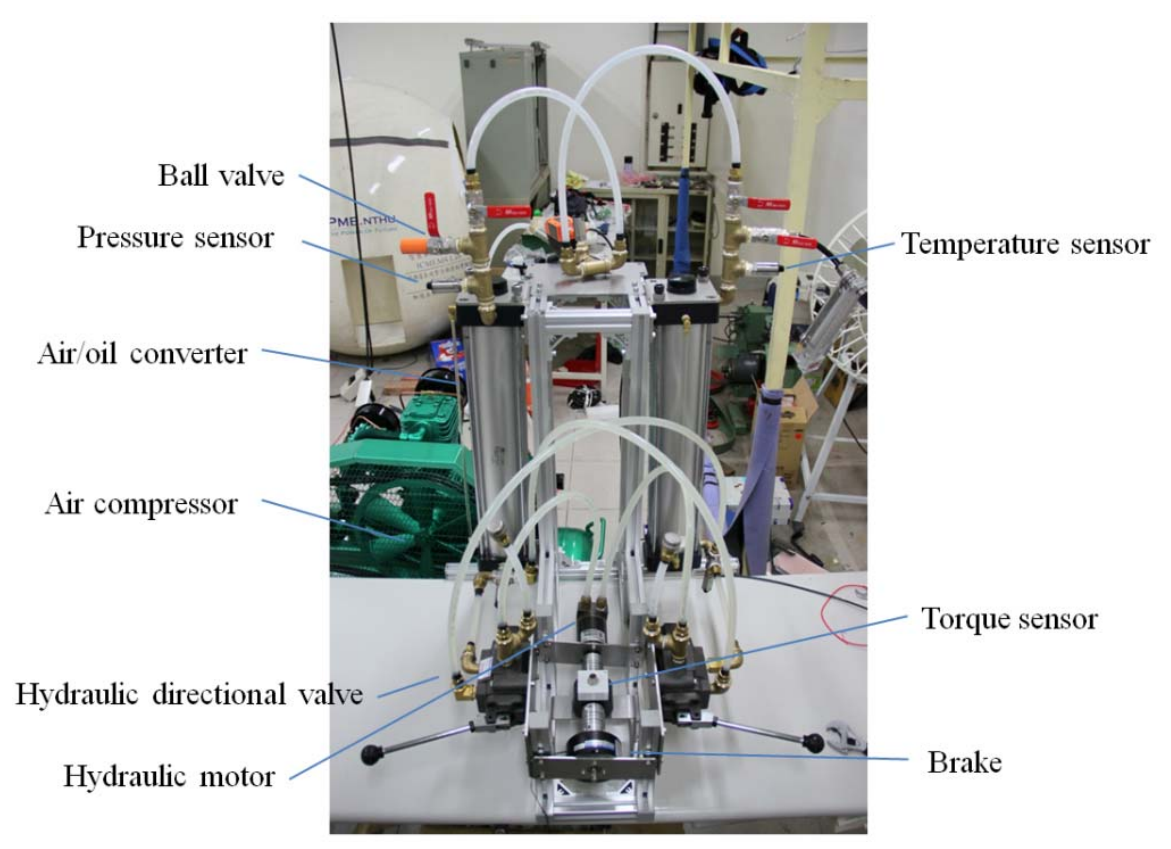

The experimental results are shown in Figure 13; the figure shows that the efficiency of the motor decreases when the rotational speed rises and the maximum efficiency at 10 bar is $62 \%$ at $200 \mathrm{rpm}$. The motor cannot rotate at a rotational speed lower than 200rpm.

\subsection{System Efficiency of Experiment}

An equation to calculate the system efficiency is necessary, but Equation (12) is not fit for this experiment. Thus, a suitable equation should be derived, as shown below.

The model is shown in Figure 14. 
Figure 13. (a) The hydraulic motor efficiency and (b) the hydraulic motor output torque and output power.

Operating pressure 10 bar

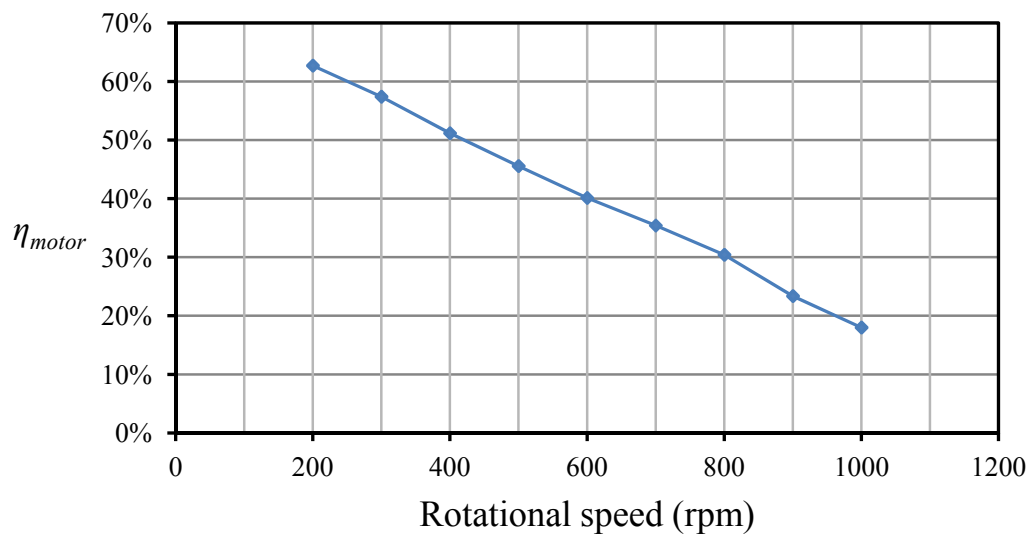

(a)

Operating pressure 10 bar

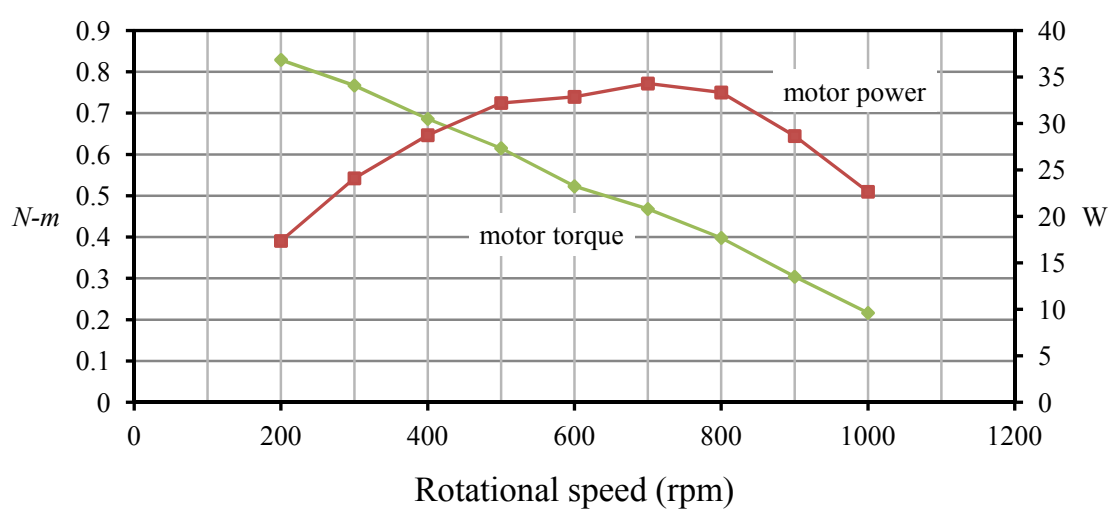

(b)

Figure 14. The energy balance of the system.




In the model, $E_{\text {tank }}$ is the energy comes from the tank which is charged into the converter; $E_{c}$ is the energy of the air in the converter exhaust to the atmosphere; $W_{\text {shaft }}$ is the work outputted by the motor. The efficiency of the system, $\eta_{\text {sys }}$, is defined as the following:

$$
\eta_{\text {sys }}=\frac{W_{\text {shaft }}}{E_{\text {tank }}}
$$

During the experiment, the initial state of the tank is at absolute pressure $P_{\text {int }}$ volume $V_{\text {tank }}$ and time $t_{\text {int }}$. Then the system works several cycles to have the work $W_{\text {shaft }}$ at operation pressure $P$ until the state of the tank becomes the final state at absolute pressure $P_{\text {fin }}$, volume $V_{\text {tank }}$ and time $t_{\text {fin }}$. To keep the operation pressure at $P$, the final pressure in the tank $P_{f i n}$ must be higher than $P$. $E_{\text {tank }}$ can be obtained from the energy difference between the initial state and final state of the tank. The total work that can be done by the whole tank of compressed air at the initial state is marked as $W_{\text {state, } i}$, and $W_{\text {state }, f}$ at the final state. The equations of $W_{\text {state }, i}$ and $W_{\text {state, } f}$ are similar to Equations (5) and (6). Then:

$$
\begin{gathered}
W_{\text {state }, i}=\frac{P_{\text {int }} V_{\text {tank }}}{1-\gamma}\left[\left(\frac{P_{\text {int }}}{P_{\text {atm }}}\right)^{\frac{1}{\gamma}-1}-1\right]-P_{\text {atm }}\left[\left(\frac{P_{\text {int }}}{P_{\text {atm }}}\right)^{\frac{1}{\gamma}} V_{\text {tank }}\right] \\
W_{\text {state }, f}=\frac{P_{\text {fin }} V_{\text {tank }}}{1-\gamma}\left[\left(\frac{P_{\text {fin }}}{P_{\text {atm }}}\right)^{\frac{1}{\gamma}-1}-1\right]-P_{\text {atm }}\left[\left(\frac{P_{\text {fin }}}{P_{\text {atm }}}\right)^{\frac{1}{\gamma}} V_{\text {tank }}\right] \\
E_{\text {tank }}=W_{\text {state }, i}-W_{\text {state }, f}
\end{gathered}
$$

The $W_{\text {shaft }}$ is the total work done by the motor during the operation and the Equation is listed as following:

$$
W_{\text {shaft }}=\int_{t_{\text {int }}}^{t_{\text {fin }}} \tau \omega d t
$$

Then the average system efficiency is defined as:

$$
\eta_{\text {sys }}=\frac{W_{\text {shaft }}}{E_{\text {tank }}}=\frac{W_{\text {shaft }}}{W_{\text {state }, i}-W_{\text {state }, f}}
$$

\subsection{System Efficiency Measurement}

\subsubsection{Constant Pressure Operation Results}

The following is the result of 10 bar of constant pressure operation, as mentioned in Section 2.1. To make the experiment similar to the theoretical model, the two hydraulic directional valves are removed in this efficiency measurement. This no longer allows the phases to change continuously; however, the experiment still works because sufficient time exists to obtain a steady output, even during one phase. At $1000 \mathrm{rpm}$, the system takes $25 \mathrm{~s}$ to finish one phase.

The efficiency $\eta_{s y s}$ calculation follows Equation (18). The operation gauge pressure is 10 bar, the absolute tank pressure reduces from $P_{\text {int }}$ at 13 bar to $P_{\text {fin }}$ at 11.52 to 11.63 bar after five cycles. The result is plotted in Figure 15, which shows that the efficiency drops with increasing rotational speed; the maximum system efficiency is $32.5 \%$ at $200 \mathrm{rpm}$. 
Figure 15. The system efficiency under the constant pressure operation.

Operating pressure 10 bar

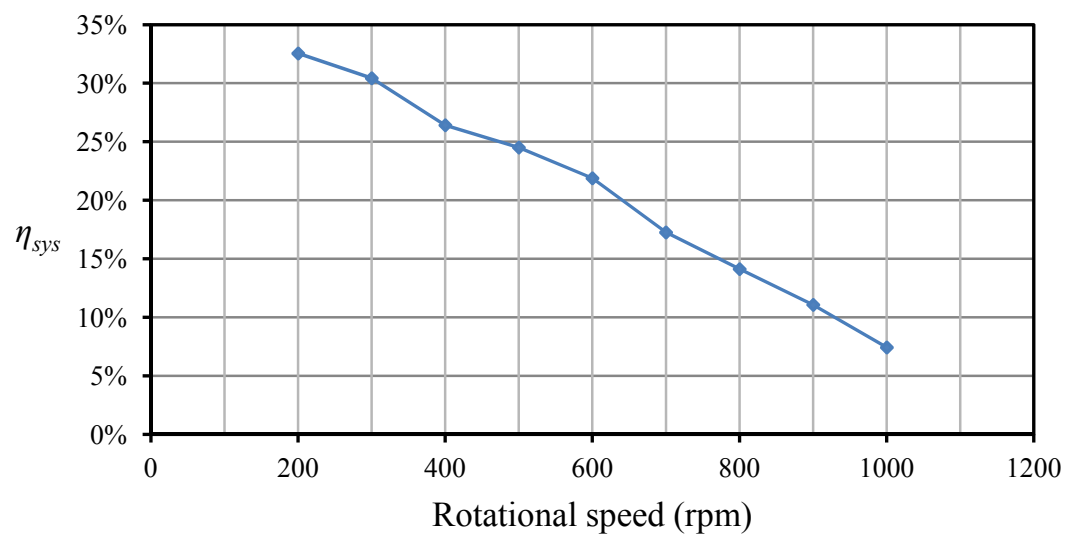

\subsubsection{Expansion Operation Results}

The operating speed is set at 200 to $500 \mathrm{rpm}$, the operating gauge pressure is at $10 \mathrm{bar}$, and the ratio $N$ is 2 . The pressure, rotational speed, and torque are measured and used to calculate the efficiency using Equation (18) and the experimental motor efficiency of Equation (12). The efficiency here is the average efficiency obtained by the measured data. Table 1 shows the experimental results after ten phase changes (five cycles). It is noted that all the pressures in Table 1 are gauge pressure. After the expansion, theoretically, the pressure in the converter should drop to a gauge pressure of 4.5 bar; however, the residual pressure is measured at 5.1 bar due to the redundant volume about $0.3 \mathrm{~L}$ at the top of the converter cannot be used. Experiment found that the motor cannot run at a speed higher than $500 \mathrm{rpm}$ at pressure lower than 5.1 bar. The air pressure and output torque changes during one phase are plotted in Figure 16.

Table 1. The parameters and results of the expansion operation experiment.

\begin{tabular}{ccccc}
\hline Operating speed & $200 \mathrm{rpm}$ & $300 \mathrm{rpm}$ & $400 \mathrm{rpm}$ & $500 \mathrm{rpm}$ \\
Operation pressure & $10 \mathrm{bar}$ & $10 \mathrm{bar}$ & $10 \mathrm{bar}$ & $10 \mathrm{bar}$ \\
Residual pressure & $5.1 \mathrm{bar}$ & $5.1 \mathrm{bar}$ & $5.1 \mathrm{bar}$ & $5.1 \mathrm{bar}$ \\
& Less than $5{ }^{\circ} \mathrm{C}$ from below room & Same as & Same as & Same as \\
Temperature drop & temperature and is almost constant & $200 \mathrm{rpm}$ & $200 \mathrm{rpm}$ & $200 \mathrm{rpm}$ \\
Charged volume & $2 \mathrm{~L}$ & $2 \mathrm{~L}$ & $2 \mathrm{~L}$ & $2 \mathrm{~L}$ \\
Ratio N & 2 & 2 & 2 & 2 \\
Average motor efficiency & $61.7 \%$ & $49.6 \%$ & $43.2 \%$ & $36.2 \%$ \\
Total output energy & $16,555 \mathrm{~J}$ & $15,102 \mathrm{~J}$ & $12,456 \mathrm{~J}$ & $10,109 \mathrm{~J}$ \\
Average output power & $13.2 \mathrm{~W}$ & $18.1 \mathrm{~W}$ & $20 \mathrm{~W}$ & $20.2 \mathrm{~W}$ \\
Initial Tank pressure & $12 \mathrm{bar}$ & $12.01 \mathrm{bar}$ & $12 \mathrm{bar}$ & $12 \mathrm{bar}$ \\
Final Tank pressure & $10.46 \mathrm{bar}$ & $10.37 \mathrm{bar}$ & $10.41 \mathrm{bar}$ & $10.35 \mathrm{bar}$ \\
Total input energy & $33,319 \mathrm{~J}$ & $35,449 \mathrm{~J}$ & $34,380 \mathrm{~J}$ & $35,653 \mathrm{~J}$ \\
Average efficiency $\boldsymbol{\eta}_{\boldsymbol{s y s}}$ & $49.7 \%$ & $42.6 \%$ & $36.2 \%$ & $28.4 \%$ \\
\hline
\end{tabular}


Figure 16. The air pressure and output torque changes during one phase at $200 \mathrm{rpm}$.

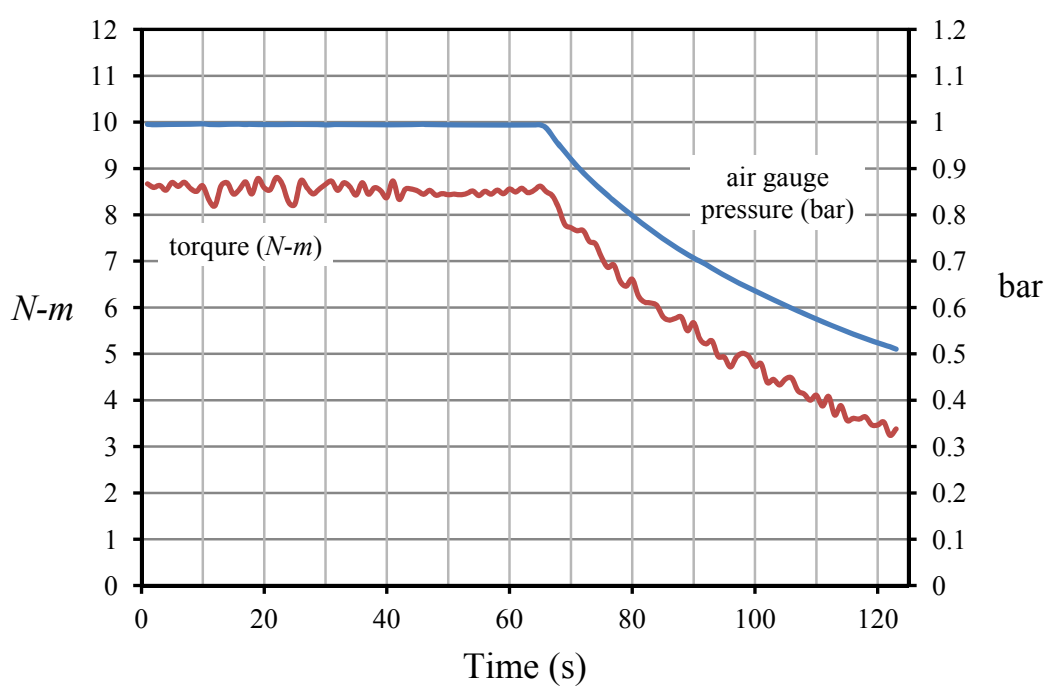

\subsection{Comparison of Theoretical and Experimental Results}

To confirm the differences between the theoretical and experimental results, the theoretical system efficiency is calculated as follows:

$$
\text { system efficiency }=\text { converting efficiency } \times \text { motor efficiency }
$$

The theoretical constant pressure-conversion efficiency obtained from Figure 6 is 52.4\%. After combining the theoretical conversion efficiency and the experimental motor efficiency obtained from Section 4.2, the theoretical system efficiencies are obtained and plotted in Figure 17. The figure shows a $0 \%-2 \%$ difference between the two results. The difference probably caused by the kinetic effect at higher rotational speed, the speed causes more fluid pressure drop. Furthermore, the accuracies of the sensors are around $0.3 \%$.

Figure 17. The comparison of theoretical and experimental results.

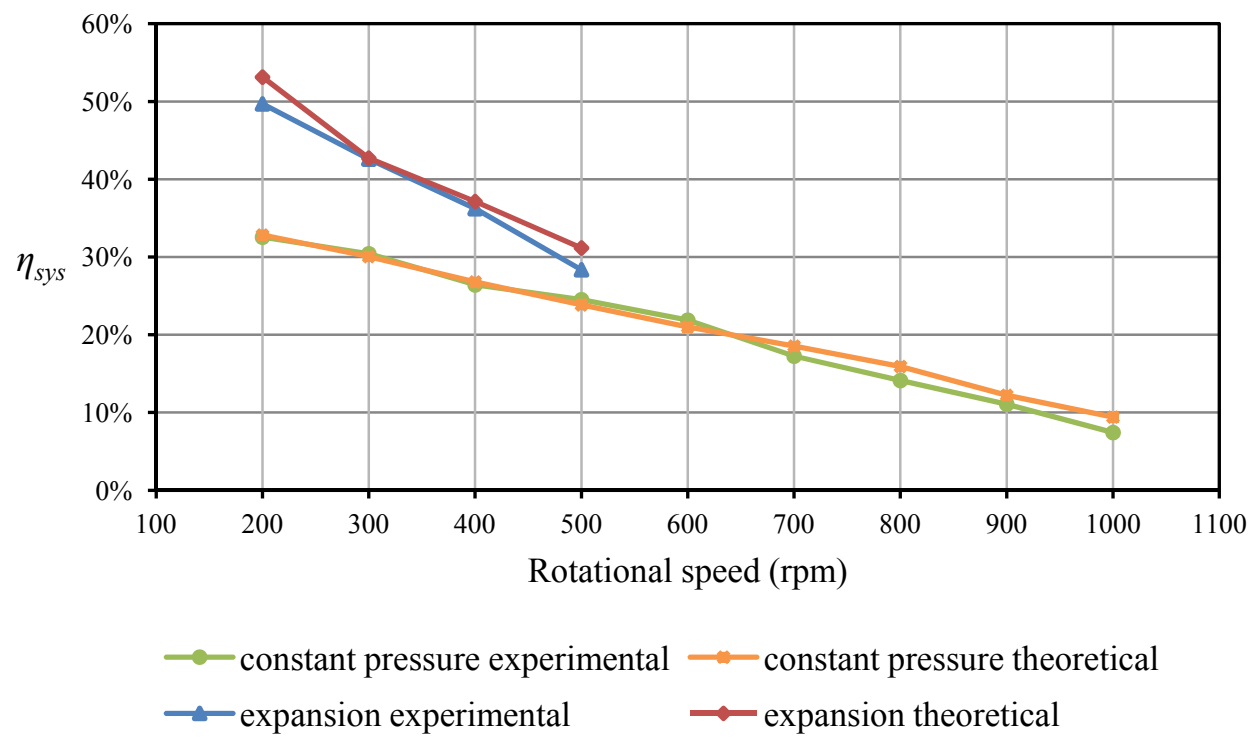


The system efficiencies under expansion operation are also plotted in Figure 17. The expansion-operation conversion efficiency is $86 \%$ from Equation (11) at a gauge pressure of 10 bar and ratio $N=2$. The experimental motor efficiency is $61.7 \%$, as obtained from Table 1 . Thus, the theoretical system efficiency of the expansion operation is $53.1 \%$, and the experimental system efficiency is $49.7 \%$ at $200 \mathrm{rpm}$. There is a $3.4 \%$ difference between the two. The difference probably caused by the temperature-drop due to the expansion in the converter. It is noted that the theorical conversion efficiency is assumed as a constant temperature expansion in the converter in Equation (9).

\section{Conclusions}

This study presented a hydraulic system driven by compressed air to demonstrate its potential to outperform a pneumatic motor in efficiency. The major parameter of efficiency under a constant pressure operation is the operating pressure; the efficiency is better with lower pressure. When the air expands in the converter, the residual pressure is also a dominant parameter. Lesser air intake leads to more heat transfer from the surrounding into the converter, thereby enhancing the efficiency. The efficiency of the air/oil conversion can be evaluated through the analysis presented in this paper. Only $0 \%-3.4 \%$ difference exists between the theoretical and experimental system efficiency, which verifies that the analysis is practical to estimate the efficiency. Therefore, these equations are helpful for determining the optimal-efficiency design and the parameters for operation. Future research will focus on system optimization and the control system.

\section{Acknowledgments}

The authors greatly appreciate the support of the National Science Council (Grant Number: NSC 100-3113-E-007-004). Without their support, this research could not have been completed.

\section{Conflict of Interest}

The authors declare no conflict of interest.

\section{References}

1. Saidur, R.; Rahim, N.A.; Hasanuzzaman, M. A review on compressed-air energy use and energy saving. Renew. Sustain. Energy Rev. 2010, 14, 1135-1153.

2. Creutzig, F.; Papson, A.; Schipper, L.; Kammen, D.M. Economic and environmental evaluation of compressed-air cars. Environ. Res. Lett. 2009, 4, 044011:1-044011:9.

3. MDI Enterprise S.A. Home Page. Available online: http://www.mdi.lu/ (accessed on 25 January 2013).

4. Ecofriend Web Page. Green Wheels: Toyota's Air Powered Ku:Rin. Available online: http://www.ecofriend.com/green-wheels-toyotas-air-powered-kurin.html (accessed on 25 January 2013).

5. O2 Pursuit. Available online: http://o2pursuitdeanbenstead.wordpress.com/ (accessed on 25 January 2013). 
6. Shen, Y.-T.; Hwang, Y.-R. Design and implementation of an air-powered motorcycles. Appl. Energy 2009, 86, 1105-1110.

7. PG\&E Web Page. Clean Energy Solutions. Available online: http://www.pge.com/about/environment/ pge/cleanenergy/ (accessed on 25 January 2013).

8. Werner, E.H. Rotary Engine. U.S. Patent No.716,970, 30 December 1902.

9. Quasiturbine Home Page. Available online: http://www.quasiturbine.com (accessed on 25 January 2013).

10. Naranjo, J.; Kussul, E.; Ascanio, G. A new pneumatic vane motor. Mechatronics 2010, 20, 424-427.

11. $\mathrm{Hu}, \mathrm{C} .-\mathrm{K}$. Investigation and Improvement of Piston Type Compressed Air Engines. Master's Thesis, National Tsing Hua University, Hsin Chu, Taiwan, 11 July 2012.

12. Requsci, A.M.C. Engine/Compressor of Compressed Gas of Free Piston and Freewheel. U.S. Patent Application Publication, U.S. 20070017218, 25 January 2007.

13. Fairley, P. Deflating the Air Car. IEEE Spectrum, 30 October 2009. Available online: $\mathrm{http}$ //spectrum.ieee.org/energy/environment/deflating-the-air-car (accessed on 25 January 2013).

14. Pietro, A.D. Rotary Piston Engine. U.S. Patent No.6,868,822, 22 March 2005.

15. Otto, T.W. Combination Air and Hydraulic Motor. U.S. Patent No. 3,779,132, 18 December 1973.

16. Wu, B.; Lin, C.C.; Filipo, Z.; Peng, H.; Assanis, D. Optimal power management for a hydraulic hybrid delivery truck. Veh. Syst. Dyn. 2004, 42, 23-40.

17. U.S. Energy Protection Agency. World's First Full-Size Hydraulic Hybrid SUV. Presented at 2004 SAE World Congress, Detroit, MI, USA, 8-11 March 2004; EPA420-F-04-019.

18. Sauer Danfoss Web Page. Orbital Motors. Available online: http://www.sauer-danfoss.com/ Products/OrbitalMotors/index.htm (accessed on 25 January 2013).

(C) 2013 by the authors; licensee MDPI, Basel, Switzerland. This article is an open access article distributed under the terms and conditions of the Creative Commons Attribution license (http://creativecommons.org/licenses/by/3.0/). 